\title{
Toward an Improved Treatment for Gastroparesis
}

\author{
Tae-Han Kim \\ Department of Surgery, Gyeongsang National University School of Medicine, Changwon, Gyeongsangnam-do, Korea
}

Article: Minimally invasive gastric electrical stimulation using a newly developed wireless gastrostimulator: a pilot animal study Kim SH, Kim HB, Chun HJ, et al

(J Neurogastroenterol Motil 2020;26:410-416)

Gastroparesis is defined as delay in gastric emptying in the absence of mechanical obstruction of the gastric outlet. ${ }^{1}$ It deteriorates patients' quality of life and nutritional status, resulting in mortality in severe cases. Accordingly, long standing diabetes was considered as typical cause of gastroparesis, however, only one-third of gastroparesis patients are developed from diabetic background and only less than $5 \%$ patients from diabetes population develop gastroparesis. $^{2}$ Main etiology of gastroparesis still remains idiopathic. ${ }^{3}$

Delivery of gastric contents from the stomach into the small bowel is the final result of sophisticate secretory events and coordinated neuromuscular stimulation in the antrum, pylorus, and duodenum. ${ }^{4}$ In addition to loss of vagal innervation, recent molecular investigations suggest that gastroparesis occurs from loss of function of interstitial cells of Cajal due to macrophage mediated immune response. ${ }^{5}$ The pathophysiologic background provides refinement and development of new techniques for studying the different aspects of gastric function is required to provide better understanding of the clinical symptoms and develop novel therapies.

Gastric electrical stimulation provides electrical pulse to facilitate the symptoms of gastroparesis. ${ }^{7}$ It is clinically proven with safety and feasibility in animal models and clinical trials. The limitation of this method is that it requires surgical implantation and postoperative morbidities such as pain, infection and so forth. In their recent scientific achievement, Kim et $\mathrm{al}^{8}$ introduced a minimally invasive gastric stimulation method with a newly developed wireless stimulator. In this study, the gastric electrical stimulation device was inserted into the alimentary tract by endoscopic procedures in pigs, and the gastric myoelectrical activity was recorded during the study. This system showed effective electrical stimulation with safe and feasible approach.

The progress made over the last decade has resulted in better understanding and promising roadmap for managing gastroparesis. However, hurdles still exist in expanding the betterment of treatment and diagnosis. For specific target treatment, future investigations will have to investigate the complex mechanisms steering the digestion process in all aspects. A combination of molecular and physiological approach may facilitate the treatment for gastroparesis, thus future strategies will hopefully lead to better prevention, treatment, and patient care with greater precision.

\section{Financial support: None.}

Conflicts of interest: None.

\section{References}

1. Parkman HP, Hasler WL, Fisher RS, American Gastroenterological

Received: June 9, 2020 Revised: None Accepted: June 12, 2020

@ This is an Open Access article distributed under the terms of the Creative Commons Attribution Non-Commercial License (http://creativecommons. org/licenses/by-nc/4.0) which permits unrestricted non-commercial use, distribution, and reproduction in any medium, provided the original work is properly cited.

${ }^{*}$ Correspondence: Tae-Han Kim, MD, PhD

Department of Surgery, Gyeongsang National University, Changwon Hospital, 11 Samjungja-ro, Sungsan-gu, Changwon, Gyeongsangnam-do 51472, Korea

Fax: +82-55-214-3776, E-mail: taehan.email@gmail.com 
Association. American Gastroenterological Association technical review on the diagnosis and treatment of gastroparesis. Gastroenterology 2004;127:1592-1622.

2. Choung RS, Locke GR 3rd, Schleck CD, Zinsmeister AR, Melton LJ 3rd, Jalley NJ. Risk of gastroparesis in subjects with type 1 and 2 diabetes in the general population. Am J Gastroenterol 2012;107:82-88.

3. Liu N, Abell T. Gastroparesis updates on pathogenesis and management. Gut Liver 2017;11:579-589.

4. Minami H, McCallum RW. The physiology and pathophysiology of gastric emptying in humans. Gastroenterology 1984;86:1592-1610.

5. Cipriani G, Gibbons SJ, Miller KE, et al. Change in populations of macrophages promotes development of delayed gastric emptying in mice. Gastroenterology 2018;154:2122-2136, e12.

6. Grover M, Gibbons SJ, Nair AA, et al. Transcriptomic signatures reveal immune dysregulation in human diabetic and idiopathic gastroparesis. BMC Med Genomics 2018;11:62.

7. Navas CM, Patel NK, Lacy BE. Gastroparesis: medical and therapeutic advances. Dig Dis Sci 2017;62:2231-2240.

8. Kim SH, Kim HB, Chun HJ, et al. Minimally invasive gastric electrical stimulation using a newly developed wireless gastrostimulator: a pilot animal study. J Neurogastroenterol Motil 2020;26:410-416. 